\title{
La ruptura de la serenidad. Apuntes sobre el reencuentro con la policromía monumental del pasado
}

\author{
Jorge RIVAS LÓPEZ \\ Universidad Complutense de Madrid
}

RESUMEN. A lo largo de las primeras décadas del siglo XIX se produjo un cambio muy significativo en la percepción que los eruditos y los artistas tenían de la arquitectura y la escultura de la Antigüedad. Los descubrimientos arqueológicos del momento, junto a la labor de artistas y arquitectos, vendrían a arrojar nueva luz sobre el arte del pasado y a demostrar que los antiguos policromaban con profusión sus manifestaciones artísticas en piedra. No sin polémica, la realidad histórica acabó por imponerse y tuvo una importante repercusión en la literatura especializada y en el arte. El artículo traza un recorrido por los principales hitos que marcaron el descubrimiento y posterior difusión de la policromía sobre piedra del pasado, al tiempo que describe la situación previa a estos hechos, marcada por una errónea visión del arte de la Antigüedad.

Palabras clave: color, escultura, arquitectura, soporte pétreo, Antigüedad, siglo XIX.

ABSTRACT. In early 1800, an important change in the perception of the architecture and sculpture of the Antiquity took place. After a long period of hegemony of the taste for the white marble, the findings of the Archaeology and the work of artists and architects showed that the classics applied a colorful polychromy to their masterpieces in stone. Despite the quarrels about this subject, the historical fact was finally assumed, and it was able to generate an important impact both in the specialized literature and in the art of the $19^{\text {th }}$ Century. The article aim to depict the main events related to the discovering and subsequent diffusion of the polychromy on stone of the Past, as well as the previous situation, characterized by a erroneous vision of the Classical art.

Key words: Color, Sculpture, Architecture, Stone, Antiquity, 19th Century.

\section{RAZONES PARA EL OLVIDO HIS- TÓRICO DEL COLOR SOBRE LA PIEDRA.}

La policromía monumental constituyó una práctica cuya relevancia histórica está hoy por encima de toda duda. El arte egipcio, el minoico y el grecorromano, entre otros, desarrollaron un conjunto de técnicas destinado a aportar variedad cromática a la arquitectura y a la escultura en piedra. El color final era el resultado de una sucesión de estratos, con mayor o menor grado de sofisticación en función de la eventual presencia de imprimación, capas pictóricas, 
veladuras, delgadas láminas metálicas, etc. Ello por no hablar de otras posibilidades con que el artista de la Antigüedad contaba a la hora de aportar cromatismo a la escultura y la arquitectura y que dejamos fuera de este artículo por cuanto no implican una verdadera secuencia estratigráfica. ${ }^{1}$ Fustes y capiteles de columnas, frisos esculpidos, arquitrabes con sus metopas y triglifos, escultura y relieves de los tímpanos, escultura exenta... El color se adhirió a estos elementos como una piel capaz de protegerlos frente a las inclemencias y contribuir al desarrollo de las formas representadas, de completar su significado simbólico e iconográfico y hacerlos reconocibles para el espectador. La policromía se constituyó, pues, en un complemento indispensable para las formas esculpidas, como lo demuestra el hecho de que en ella se involucrasen pintores de prestigio. ${ }^{2}$

A pesar de que el policromado de la piedra fue una práctica cotidiana en la Antigüedad, es un hecho que el conocimiento erudito de la misma permaneció aletargado durante un amplio periodo de la Historia. Aunque el desarrollo del arte medieval occidental propició, a partir del siglo XII y como consecuencia del desenvolvimiento de la gran escultura monumental románica y gótica, un extraordinario desarrollo de la policromía sobre piedra -coincidente en

\section{-}

${ }^{1}$ Entre ellas la técnica acrolítica y el polilitismo, ambas dotadas de una fuerte raigambre clásica y que consiguen efectos cromáticos mediante la combinación de materiales pétreos de diferentes colores y características. Por motivos aún más obvios, la técnica crisoelefantina y la toréutica no tienen cabida en estas páginas.

${ }^{2}$ Plinio el Viejo, al tratar de la pintura de género de los griegos, señalaba a Nicias como policromador de estatuas: «Este era el Nicias del que decía Praxíteles, cuando se le preguntaba qué obras de mármol merecían su consideración más alta, "aquellas en las que Nicias ha metido su mano"; tanta era la importancia que atribuía a los detalles pintados por éste». PLINIO EL VIEJO, Historia Natural, Libro 35, en la edición de E. TORREGo, Plinio, Textos de Historia del Arte, Madrid, 2001, p. 116 muchos puntos con la practicada en la Antigüedad en lo que concierne a sus funciones y significados- ${ }^{3}$ las asunciones estéticas del Renacimiento, afianzadas en los siglos posteriores, confirmaron la hegemonía de la piedra al natural. En efecto, con la introducción del pensamiento y la estética renacentistas se registró un retroceso paulatino del interés hacia los efectos que el color y el brillo del oro podían aportar a la escultura y la arquitectura. A pesar de que en el alto Renacimiento se impuso una entronización del ideal clásico, plasmado en obras que con frecuencia constituían una verdadera imitación del estilo antiguo, el arte en piedra del pasado fue percibido en los colores propios del material desnudo, desprovisto de policromía. Entre los factores que explican este hecho cabe citar la posibilidad de que todo rastro de color hubiese desaparecido en el transcurso de los siglos como consecuencia de su continua exposición a la intemperie, o debido a una larga permanencia bajo tierra. Por otra parte, los modelos clásicos en que estos artistas se basaban eran fundamentalmente de factura romana, pueblo que empleó la policromía sobre piedra con menor profusión que el griego. Pero además, los modelos clásicos directos de que disponían los artistas italianos a fines del periodo medieval fueron muy limitados. En el mejor de los casos tuvieron acceso a los hallazgos procedentes de los yacimientos romanos que por entonces comenzaban a ser explorados. ${ }^{4}$ Los restos

-

${ }^{3}$ Una descripción en profundidad de los posibles significados y funciones inherentes a las policromías aplicadas a la piedra en la Antigüedad y la Edad Media puede encontrarse en J. RIVAS, Policromías sobre piedra en el contexto de la Europa medieval. Aspectos históricos y tecnológicos, tesis doctoral inédita.

${ }^{4}$ Artistas como Donatello y Brunelleschi excavaron en busca del arte del pasado en los restos de la Roma antigua ya en el siglo XV. No obstante, las muestras de la escultura antigua llamadas a tener una influencia determinante en la inspiración de los artistas renacentistas no hicieron su aparición hasta el fin de siglo o comienzos del siguiente: el Laocoonte no fue 
de Pompeya y Herculano, donde los artistas del Renacimiento hubiesen podido encontrar elementos suficientes como para comprender la importancia del color sobre la piedra en el arte del pasado no serían explorados hasta dos siglos más tarde. ${ }^{5}$ Otro tanto podría decirse de los yacimientos de Magna Grecia, que no comenzaron a estudiarse sistemáticamente sino a comienzos del siglo XIX. ${ }^{6}$ Por otro lado, el hecho de que la fuente principal de irradiación hacia Europa de las nuevas tendencias artísticas fuese Italia, parte de cuyos territorios no adoptaron nunca plenamente el policromado de la piedra ${ }^{7}$, contribuyó decisivamente a la progresiva expansión del gusto por el material desnudo. En este sentido, sabemos que en Florencia la talla del mármol fue considerada como la más noble expresión de la escultura, en detrimento de otras modalidades de este arte tales como el modelado o el vaciado en bronce, ambos practicados extensamente en Venecia. ${ }^{8}$ Por

descubierto hasta 1506, en las Termas de Tito, y fue mandado colocar por Julio II en el patio del Belvedere, junto a otras importantes estatuas ya en su poder, como el Apolo, descubierto en 1495 y el Torso Belvedere, descubierto a mediados del siglo XV (aunque de escasa difusión en un primer momento); el Antínoo del Belvedere, por su parte, no consta en ninguna mención hasta 1543, por lo que debió ser descubierto sólo poco tiempo antes.

${ }^{5}$ Herculano comenzó a explorarse en 1738 y Pompeya en 1748 (a pesar de haber sido descubierta mucho antes, en 1628).

${ }^{6}$ Es significativa la presencia de policromía arquitectónica y escultórica en los restos de los templos de Selinunte y otras ciudades griegas de Sicilia.

${ }^{7}$ En el norte de Italia, las influencias francesa y germánica hicieron que proliferase el policromado de la piedra durante el románico y el gótico, procedimiento artístico estrechamente ligado a la maniera tedesca o bárbara que relataba Vasari en sus Vidas.

${ }^{8}$ En este sentido marcaría la pauta tempranamente Alberti en la introducción a De Statua, el primer tratado dedicado a la escultura, donde condicionaba el título de escultor al tallista que trabaja sustrayendo al bloque de piedra la masa superflua bajo la que subyacería -en potencia- la figura. Más adelante, Miguel Ángel equipararía los modeladores a los pintores, al declarar en una carta dirigida al poeta e historiador otro lado, en los debates mantenidos a propósito del paragone entre la escultura y la pintura, tema recurrente en la Italia del siglo XVI, el argumento del color aparecía como uno de los factores clave a la hora de inclinar la balanza. Benedetto Varchi hablaba en 1546 ante la Academia de Florencia a propósito de la cuestión: « ¿Cuál será más noble, la escultura o la pintura?»:

«Las dos artes imitan a la Naturaleza. Ambas pueden, pues, imitar dos cosas que se encuentran en todos los cuerpos: la sustancia y los accidentes ["la sostanza e gli accidenti"]. Los escultores imitan más la sustancia que los accidentes. Los pintores, más los accidentes que la sustancia.»"

Avanzado el siglo, Vincenzo Borghi$\mathrm{ni}^{10}{ }^{10}$ declaraba en Selva di notizie (1564):

"Cuando dije que los colores no convienen a los escultores, no quería decir que los escultores no pudiesen colorear sus figuras como hacen los que trabajan en cera o en escayola. Pero la fuerza del escultor ["la virtù"] reside en el escoplo, y si algún torpe se sirve de los colores, se apartará de la naturaleza de este arte.» ${ }^{11}$

Tanto Varchi como Borghini, integrados en la corriente neoplatónica florentina, proclaman, pues, la superioridad de los escultores sobre los pintores, fundamentándola en dos razones principales: en pri-

Benedetto Varchi en 1546: «Al decir escultura me refiero al tipo que se ejecuta mediante la extracción; el que se realiza mediante la construcción se parece a la pintura» (M. BARASH, Teorías del arte, Madrid, 2001, p.142).

${ }^{9}$ W. SAUERLÄNDER, «Quand les statues étaient blanches», La Couleur et la Pierre. Polychromie des portails gothiques, actas del Coloquio de Amiens (2000), París, 2002, p.28.

${ }^{10}$ El clérigo Raffaello Borghini, contemporáneo de Vincenzo Borghini, recogería en Il Riposo (1584) todos los argumentos esgrimidos hasta el momento en favor de la pintura o la escultura.

${ }^{11}$ P. BAROCCHI (editora), Benedetto Varchi, Vincenzo Borghini, Pittura e Scultura nel Cinquecento, Livorno, 1998, p.115. 
mer lugar, los escultores, al prescindir de los colores para sus estatuas, practican un arte «puro», sin artificios, donde no se pretende engañar al espectador por medio de la imitación de los accidenti ni a través de la seducción de los colores; por otro lado, la verdadera escultura ha de basarse única y exclusivamente en la labor de talla. La policromía quedaría así relegada al ámbito de la artesanía popular o para los trabajos decorativos realizados en serie. ${ }^{12}$

Ya en pleno barroco, el erudito Giovanni Bellori, expresaba así su opinión acerca de los colores naturalistas en el arte:

«La gente común [las clases populares] relaciona todo lo que ve con el sentido visual. Admiran las cosas pintadas con naturalidad, pues están acostumbrados a ellas; les gustan los bellos colores.» 13

A mediados ya del siglo XVIII, las creaciones arquitectónicas, la actividad de los anticuarios y las publicaciones arqueológicas, junto con la adopción de un vocabulario formal de lo antiguo, iban preparando el terreno para la estética neoclásica. ${ }^{14}$ Desde el enfoque que nos ocupa, una

\section{-}

${ }^{12}$ Dentro de esta categoría inferior quedarían englobados, por poner ejemplos representativos del periodo, «las figuras de belenes napolitanos, las imágenes en cera e incluso la escultura en madera de las iglesias barrocas de Alemania o de Austria» (W. SAUERLÄNDER, Op.cit., p. 29). De esta última afirmación se infiere que la secular tradición escultórica española en madera policromada y estofada entraría de pleno bajo la categoría del «gusto vulgar», bajo la mirada de los florentinos.

${ }^{13}$ G. BELLORI, Idea, citado en M. BARASH, Op cit. p. 225.

${ }^{14}$ Será en este periodo cuando comienzan a desarrollarse importantes trabajos en enclaves arqueológicos (Herculano, Pompeya, Spalato, etc.) que vinieron a redundar en el gusto por lo antiguo. Estas excavaciones dieron lugar a la edición de los ocho volúmenes de Antichità di Ercolano esposte (Nápoles 1752-92), publicados progresivamente en Inglaterra, Francia, Alemania e Italia. En Nápoles se fundó, en 1755 y por orden de Carlos VII (posteriormente Carlos III de España), la Reale Accademia Ercolanense, con la misión de publicar de las consecuencias de este proceso de asimilación del mundo clásico fue la confirmación del mármol blanco como el material idóneo para la creación artística. Sus virtudes en estado puro serían llevadas a la luz de la estética neoclásica hasta la sublimación, capaces, sólo ellas, de comunicar a las obras de arte el aire de «noble simplicidad y serena grandeza» que podía hallarse en el arte de la Antigüedad. ${ }^{15}$ Sin embargo, sabemos que para los artistas neoclásicos con más proyección, la imitación del arte antiguo no estaba llamada a ser un fin en sí misma, sino más bien «un medio de crear obras ideales de validez universal y eterna». ${ }^{16}$ En su búsqueda permanente de la «verdad» que subyacía en las obras antiguas, se centraron más, al imitarlas o interpretarlas, en la forma y en la línea que en la textura o el color. Tanto las cualidades texturales como la presencia de coloración -no digamos ya de una policromía en toda regla- vendrían a ser, para los neoclásicos, elementos distorsionantes de la verdadera

los hallazgos de Herculano. Roma, por su parte, se convirtió en el epicentro de las inquietudes de Reynolds, Piranesi, Le Lorrain, Clarisseau, o Robert Adam, «sostenidas por instituciones como las academias de San Lucas y de Francia, donde la relectura de los ejemplos antiguos conducía al replanteamiento del lenguaje arquitectónico» (G. TEYSSOT, «Ilustración y arquitectura. Intento de historiografía», en AA.VV., Arte, arquitectura y estética en el siglo XVIII, Madrid, p. 110). También Nápoles estaría llamada a convertirse en una de las capitales del Neoclasicismo, pues a ella se habían dirigido en las mismas fechas los enviados de Mme. de Pompadour, Vendières, Leblanc, Cichin y Soufflot y, algo más tarde, el propio Winckelmann, en diversas ocasiones desde 1758 .

${ }^{15}$ Mediante la fórmula eine edle Einfalt und eine stille Grösse (una noble simplicidad y una serena grandeza) Winckelmann defendía un retorno al espíritu de la Antigüedad, aunque no llevado al pie de la letra sino como una fuente de inspiración para llevar a cabo obras de validez eterna y universal.

${ }^{16}$ H. HonOUR, Neoclasicismo, Madrid, 1991, p. 144. En este sentido, Honour afirma que en el deseo de llegar a ser tan inimitables como los creadores antiguos, los artistas neoclásicos «se consideraban, no simples revivalistas de lo griego o lo romano, sino restauradores del verdadero estilo» (Ibídem., p. 145). 
naturaleza de la obra artística, que debía ser capaz de comunicar un sentimiento común a todos los espectadores que la contemplasen. En relación a este punto, los artistas neoclásicos,

«Eran muy precavidos con los efectos coloristas y texturales, no sólo porque eran superficiales sino también porque solamente se podian aprehender por los sentidos y por tanto aparecían diferentes a las distintas personas. Les desagradaban por lo mismo los trucos ilusionistas y las sutilezas atmosféricas.» $^{17}$

Este hecho se verificaba no sólo en las creaciones inspiradas en la Antigüedad, sino que era extensible a los facsímiles de originales famosos solicitados por los clientes, originales que en muchos conservaban aún trazas de color suficientes como para tentar a una recreación de su policromía Tal fue el caso, por poner un ejemplo paradigmático, de los mármoles de Lord Elgin procedentes del Partenón:

«Las verdades sobre el arte clásico que estaban siendo reveladas mediante la exposición de obras originales, como los mármoles del Partenón, parecieron haber tenido muy poco efecto [...], aunque los artistas fueron los primeros en darse cuenta de su valor. $O$ bien suponían un desafío demasiado grande, $o$ bien no había una necesidad manifiesta de imitarlos.» 18

Importantes fueron también para el tema que nos ocupa las relaciones establecidas entre la escultura y el dibujo a lo largo del Neoclasicismo. En este sentido, la escultura neoclásica, al tener como una de sus principales características «el abandono de los contrastes y la aspiración a la elegancia de la línea creada por el volumen visto de perfil», ${ }^{19}$ participaría en cierto modo del

\footnotetext{
${ }^{17}$ Ibídem., p. 146.

18 J. BOARDMAN, El arte griego, Madrid, 1997, pp. 193-194.

${ }^{19}$ M. PraZ, Gusto neoclásico, Barcelona, 1982, p.
}

interés por la línea pura. No conviene olvidar además el hecho de que en una nación como Inglaterra, que tan decisiva influencia tuvo en la difusión del gusto neoclásico, la práctica de la escultura estuvo caracterizada por el predominio de una componente bidimensional, expresada en el relieve, por encima de la tridimensionalidad de las figuras de bulto redondo.

Por otro lado, la aparente ausencia de referencias explícitas al policromado de la piedra en los textos antiguos habría venido a redundar en el decidido partido por la blancura del mármol que tomaron los eruditos y los artistas desde el Renacimiento. ${ }^{20}$ Por añadidura, las críticas vertidas por determinados autores clásicos hacia los excesos en la decoración vinieron a confirmar a los neoclásicos en su rechazo de los efectos que el color podía aportar a la escultura. En este sentido, Plinio y Vitrubio habían sido especialmente críticos con el gusto «alejandrino» y sus excesos ornamentales, abominando de toda decoración que apelase a los sentidos y estuviera ayudada por colores impuros, o de engañosos trucos ilusionistas. Estos testimonios de la Antigüedad estarían llamados a ejercer una considerable influencia en la percepción del arte antiguo en general y en el rechazo del ornamento por parte de los estetas del Neoclasicismo.

\section{EL DESCUBRIMIENTO DE LA PO- LICROMÍA SOBRE PIEDRA DEL PASADO.}

Un paso fundamental para el recono-

\footnotetext{
169.

${ }^{20}$ En las primeras décadas del s. XIX, Quatremére de Quincy, J.I. Hittorf, F. Kugler y otros defensores de la policromía monumental desmontaron la afirmación de los neoclásicos en este sentido, aportando citas de autores antiguos donde se hacía referencia expresa al policromado de la escultura y la arquitectura en piedra: Platón (La República IV, 420 c-d), Plinio el ViejO (Historia Natural, XXXV) o PUTARCO (De gloria Atheniensum 6; 348E), entre otros.
} 
cimiento del importante papel de la policromía monumental en la Antigüedad fue el descubrimiento de la estatuaria y la arquitectura policromadas griegas a fines del siglo XVIII, circunstancia que se vio favorecida por la creación de comités de arqueología en las principales naciones europeas y por la fundación de sociedades filo helénicas. Pero la nueva consideración del arte del pasado no sólo estará avalada por las informaciones aportadas por los descubrimientos arqueológicos, sino también por el despertar del espíritu romántico que caracterizó al periodo. Así, aunque los nuevos puntos de vista en la percepción del arte antiguo eran básicamente científicos, tras ellos «estaba también el amor por las ruinas en general de los románticos y la intensidad poética de aquel enclave concreto» ${ }^{21}$. En esa coyuntura finisecular, la sociedad europea comenzaba, pues, a discutir temas que la estética neoclásica había considerado hasta entonces cerrados e incuestionables. Todas estas circunstancias favorables hicieron posible que a lo largo de la primera mitad del siglo XIX, el público erudito aceptase gradualmente el hecho de que la arquitectura y la escultura griegas hubiesen estado pintadas.

La primera referencia expresa al color aplicado sobre la piedra se remonta a la década de 1780, cuando el anticuario Richard Chandler ${ }^{22}$ y otros continuadores de los trabajos de Stuart y Revett revelan la presencia de la policromía monumental griega en los tomos de The Antiquities of Athens. ${ }^{23}$ En esa misma década, las notas de

${ }^{21}$ H. HONOUR, Op. cit., p. 216.

${ }^{22}$ Richard Chandler (1738-1810), anticuario británico, exploró junto con Revett las antigüedades de Jonia y Grecia, por intermedio de la Society of Dilettan$t i$, sociedad formada por nobles y caballeros que promovió el estudio del arte griego y romano.

${ }^{23}$ Ya en el año 1780 se conocían al menos tres edificios atenienses de fines del siglo $\mathrm{V}$ a.C. donde podían hallarse restos significativos de policromía arquitectó- viaje de Louis Fauvel, ${ }^{24}$ cónsul de Francia en Atenas constatan que los bajorrelieves del Partenón y el Teseion, estaban profusamente pintados:

"Los bajorrelieves de estos dos templos estuvieron pintados; cada objeto tenía su propio color: las carnaciones, los paños, los fondos; he podido observar vestimentas púrpuras, pileus o sombreros pintados de verde; el fondo de estos bajorrelieves era azul [...]» ${ }^{25}$

A comienzos del siglo XIX, los arquitectos británicos E.D. Clarke y E. Dodwell ${ }^{26}$ dejan testimonio en sus cuadernos de viaje de las policromías sobre piedra que pudieron observar sobre los mármoles procedentes del Partenón. Otros viajeros ingleses siguieron esta misma línea durante el primer decenio del siglo, como los también arquitectos W. Gell y J.P. Gandy ${ }^{27}$, quienes prestaron especial atención a los frisos grabados y pintados. De nuevo Fauvel, anotaría en 1811 que la policromía se hallaba también presente sobre las estelas funerarias griegas. En ese mismo año, el sueco J.D. Akerblad ${ }^{28}$ comunicaba oficialmente al mundo erudito que las esculturas del Partenón y del Teseion estuvieron pintadas. Nuevos descubrimientos arqueológicos vinieron a sumarse a los anteriores. Entre ellos podemos citar, además de los ya mencionados de la Acrópolis ateniense, que se mantuvieron a lo largo de todo el siglo

nica que revelaban que los griegos pintaban las partes superiores de los templos clásicos.

${ }^{24}$ Fauvel, Louis. Fue rival de Lord Elgin y trabajó al servicio de Choiseul-Gouffier, miembro de la Académie des Inscriptions y autor de Voyages pittoresques.

${ }^{25}$ M.F. BILLOT: «Recherches aux 17e et 19e sur la polychromie de l'architecture grecque», Paris-RomeAthènes, Le Voyage en Grèce des Architectes français aux 19e et 20e siècles, ENSBA, París, 1982.

26 Edward DODWELL (1767-1832), viajero y arqueólogo, autor de A Classical and Topoghrapical Tour throught Greece (1819).

${ }^{27}$ William GeLL (1777-1836) y John Peter GANDY (1787-1850), arquitectos británicos.

${ }^{28}$ Johan David Akerblad (1763-1813) 
$\mathrm{XIX}^{29}$, las esculturas del templo de Afaia, en Egina, descubiertas por el arquitecto y arqueólogo C.R. Cockerell -también en 1811y que fueron trasladadas a Munich. Cockerell, activo en las ruinas de Egina, Atenas y Siracusa, reveló la existencia de policromías en estos enclaves en 1812 y descubrió ese mismo año los vestigios también policromados del templo de Apolo Epicuro en Bassae. En 1822-23 los arquitectos ingleses W. Harris y S. Angell, a instancias del cónsul inglés en Palermo, Fargan, comienzan las excavaciones en las ruinas de Selinunte, descubriendo tres metopas policromadas del templo "C"; el año siguiente, Jakob Ignaz Hittorf, arquitecto alemán y futuro defensor de la policromía monumental, descubre el templo "B", poniendo en evidencia los restos de color aún presentes sobre la piedra, al tiempo que mide y dibuja todas las construcciones selinuntianas junto a su discípulo Zanth y al arqueólogo Stier. Las esculturas y fragmentos de frisos del Mausoleo de Halicarnaso, cuyo destino final fue el British Museum, aportaron también importantes testimonios, debido a los restos de policromía que aún subsistían en ellos. Ya en el último cuarto del siglo XIX, las excavaciones de Heinrich Schielemann en Troya, Micenas y Tirinto y de Arthur Evans en Creta dan a conocer el mundo minoico-micénico. Estos descubrimientos confirmaban la profusión con que el color se aplicó sobre la piedra:

«El descubrimiento de los restos preclásicos de Micenas y Knossos en la segunda mitad del siglo XIX reforzó la imagen de que el mundo griego había siempre demostrado un gran interés por el color.» ${ }^{30}$

${ }^{29}$ A manera de ejemplo, en 1863 se descubrieron estatuas votivas y escultura arquitectónica del periodo Arcaico en la Acrópolis de Atenas, con numerosos restos de pigmentos.

${ }^{30}$ J. GAGE, Color y cultura. La práctica y el significado del color de la Antigüedad a la abstracción, Madrid, 1993,
A pesar de la manera en que parte de estos monumentos fueron tratados en su lugar de destino ${ }^{31} \mathrm{y}$ de prejuicios muy arraigados en la sociedad de la época «acabaron siendo apreciados en su verdadero valor, y ejercieron una intensa influencia entre los artistas, y también en las ideas tanto populares como eruditas sobre Grecia». ${ }^{32}$

No obstante, tanto en la reivindicación de la importancia histórica de la policromía monumental como en las restituciones que de ella se hicieron se verían involucrados otros elementos, además de las escasas muestras de color aún supervivientes. Entre ellos serían especialmente relevantes determinados objetos encontrados en los yacimientos arqueológicos, como las representaciones humanas e imitaciones de entablamentos dóricos realizadas en terracota policromada, que repetían los motivos ornamentales pintados en las vestiduras y sobre los elementos arquitectónicos de los monumentos reales. Contribuirán también a este propósito los vasos de cerámica con representaciones arquitectónicas y escultóricas, en especial aquellas que reproducen los coronamientos policromados de los templos, así como los detalles de la indumentaria. Más aún, en el Metropolitan Museum de Nueva York puede contemplarse un vaso en el que un pintor se esmera en el policromado de una estatua de mármol, lo

p. 11.

31 Comenzaron a alzarse voces críticas hacia la manera en la que fueron conservados y expuestos los primeros conjuntos escultóricos que procedentes de Grecia y su entorno habían llegado a los museos de toda Europa. Sirvan como ejemplo paradigmático de esta destrucción de los vestigios de color preexistentes en los mármoles procedentes del Partenón -los célebres mármoles de Lord Elgin- adquiridos por el British Museum y expuestos desde 1817. Estas piezas sufrieron lavados y vaciados repetidos (la última limpieza envuelta en polémica se remonta a una fecha tan cercana a nosotros como la de 1939) que terminaron por decapar las películas pictóricas.

32 J. BOARDMAN, Op.cit, pp. 19-20. 
que da fe de lo habitual de estos procedimientos en el arte griego (Fig. 1).

A los vestigios de color que se iban descubriendo en los yacimientos arqueológicos de origen griego vinieron a sumarse los pertenecientes a otras civilizaciones de la Antigüedad. Este fue el caso de la escultura y arquitectura egipcias, cuyo conocimiento y estudio por parte de los europeos cobró un decisivo impulso de la mano de las campañas militares de Napoleón ${ }^{33}$. La policromía de los monumentos y estatuaria egipcios atrajo poderosamente la atención de artistas y diseñadores de toda Europa, sirviendo en muchos casos de clara inspiración para sus obras. ${ }^{34}$ En este sentido se pronunciaba Owen Jones mediado el siglo XIX:

«La arquitectura de los egipcios está enteramente policromada: [ellos] lo pintaban todo; tendríamos, por tanto, mucho que aprender de ellos en esta materia. Procedían mediante tintas planas, y no utilizaban ni matices ni sombras.» ${ }^{35}$

-

${ }^{33}$ La campaña militar de Napoleón estuvo acompañada de una Comisión de Ciencias y artes formada por ciento sesenta y siete técnicos y científicos dirigidos por Vivant Denon, que desde junio de 1798 hasta septiembre de 1802 recorrió prácticamente todo Egipto, estudiando y dibujando sus monumentos.

34 Sirvan como ejemplo las decoraciones «neo egipcias» aplicadas a los interiores de muchos edificios europeos del momento.

35 O. JONES, The Grammar of Ornament, Londres, 1856, pp. 24-25. Este autor diferencia claramente el carácter de la policromía arquitectónica en Grecia de su homóloga Egipcia, poseedora, esta última de un importante significado simbólico: «La ornamentación griega [...] estuvo ausente de significación, fue puramente decorativa, nunca representativa, y difícilmente podría calificársela de "constructiva"; a menudo, las diversas partes de un monumento griego presentan superficies delicadamente diseñadas para recibir ornamentación, que fue, al principio, simplemente pintada, y en los últimos tiempos, esculpida y pintadaLa ornamentación no formaba parte de la construcción, como sí ocurría con los egipcios: podría eliminarse y la estructura permanecería inmutable» (Ibídem., p. 33).
Por lo que respecta al arte romano y para aportar un ejemplo especialmente remarcable, en 1863 se produjo el descubrimiento de la estatua de mármol del emperador Augusto, en Prima Porta, con numerosos restos de policromía. Pues bien, a través de todos estos hallazgos comenzará a cambiar la imagen firmemente establecida de la blancura inmaculada de la escultura antigua, proceso que culminaría -tras arduos debates entre los intelectuales- con el reconocimiento de la importancia decisiva de la policromía en la arquitectura y escultura clásicas al nivel de las instituciones eruditas europeas.

A este resultado contribuyeron de manera decisiva las publicaciones que recogieron directa o indirectamente los descubrimientos de la arqueología a todo lo largo del siglo XIX. En Le Jupiter Olympien (1814), el polifacético Quatremère de Quincy daba paso a una nueva interpretación del arte de la Antigüedad, siendo el primero en establecer el empleo de la toréutica y la policromía escultórica entre los griegos. ${ }^{36}$ Más adelante y tras los levantamientos de las ruinas de Paestum por Labrouste (1829), destacamos el primer volumen de la Expedition Scientifique de Morée (1832), que recogía los estudios llevados a cabo por la Comisión de Ciencias y Artes que acompañaba a la campaña militar francesa por la causa de la independencia griega. En él se incluyen notables reconstrucciones de policromía monumental del Peloponeso, el Ática y las Cícladas. Poco antes, y en la Acádemie des inscriptions del Instituto de Francia, J.I. Hittorf había dado lectura a la Mémoire sur l'architecture polychrome chez les Grecs (1830), origen de su posterior Restitution du temple d'Empedocle à Selinonte ou

\footnotetext{
${ }^{36}$ No obstante, sus estudios en este sentido se centrarán en la policromía escultórica generada por medio de la combinación de diferentes materiales polícromos, una suerte de «marquetería de piedras», y no tanto en una verdadera pintura ejecutada sobre la piedra.
} 
l'Architecture polychrôme chez les grecs (1851). En esta publicación, Hittorf recoge importantes testimonios acerca del debate a que dio lugar el tema de la policromía sobre piedra en el arte antiguo, e incluye diversas láminas que restituían el color a edificios del mundo clásico, el Partenón entre ellos (Figs. 2 y 3).

Muy relevantes serían las investigaciones del arquitecto alemán Gottfried Semper, quien merced a las experiencias recogidas en sus viajes por Italia y Grecia publicó una breve obra en 1834 bajo el título Vorläufige Bemerkungen uber bemalte Architektur und Plastik bei den Alten (Observaciones preliminares sobre la arquitectura y la escultura policromada de los antiguos) y dos años después Anwendung der Farben in der Architektur und Plastik, (Empleo de los colores en la arquitectura y la escultura), convirtiéndose en uno de los más reconocidos defensores de la policromía monumental (Fig. 4). Casi al mismo tiempo, su compatriota Franz Kugler, eminente historiador y poeta, presentaba un escueto estudio sobre la policromía en la escultura y la arquitectura griegas, Über die Polychromie der griechischen Arkitektur und Skulptur und ihre Grenzen, (Acerca de la policromía de la arquitectura y la escultura griegas y de sus límites), donde pueden encontrarse descripciones de los colores que aún eran visibles sobre diversos monumentos griegos (Fig. 5).

Por su parte, el pintor y dibujante escocés David Roberts (1796-1864), tras permanecer 11 meses viajando por Egipto, Siria y Tierra Santa, publica, a partir de 1840 y en colaboración con el litógrafo Louis Haghe, numerosas láminas de Egipto donde plasma el color sobre la piedra, aún bien visible en buena parte de sus monumentos, trabajo que le proporcionó gran fama en Gran Bretaña y otros países. Poco después se publicará en París la obra de Jacques-Martin Tétaz titulada Memoire explicatif et justificatif de la restauration de
l'Erechtheion (1843), donde figuran varias reconstrucciones del color de este edificio ateniense. En The Grammar of Ornament (1857), Owen Jones establecerá analogías -y diferencias- entre la policromía arquitectónica de Grecia y de Egipto, incluyendo láminas con ejemplos de ambas (Fig. 6). En la década siguiente destaca la monografía de Georg Treu sobre las esculturas del Templo de Zeus en Olimpia (1863), donde el autor presta una notable atención a su policromía original. Ya en 1886, Ludwig Fenger publicará Dorische Polychromie (Policromía dórica), obra que consta de planchas que reproducen policromías escultóricas y arquitecturas pintadas y entre las que destaca la primera reconstrucción de la policromía original del Augusto de Prima Porta, por Georg Treu. De hecho, el espíritu del positivismo científico propició el periodo más fecundo en el estudio de la policromía escultórica y en el que los restos de color supervivientes fueron descritos y dibujados con gran meticulosidad. A este respecto, y a partir de 1870 jugó un importante papel la familia Guilliéron (Emile Guilliéron padre e hijo), artistas -y «restauradores»- suizos establecidos en Grecia que trabajaron para Evans, realizando numerosos dibujos de esculturas antiguas.

\subsection{Primeras aportaciones de la ciencia}

También a comienzos del siglo XIX se desarrollan los primeros análisis científicos tendentes a contrastar las observaciones de los arqueólogos y los arquitectos a propósito de la policromía sobre piedra. ${ }^{37}$ Las

\footnotetext{
${ }^{37}$ Como es lógico, el estudio de la tecnología de la policromías en piedra constituyó sólo una parte de las investigaciones que sobre técnicas pictóricas del mundo antiguo se desarrollaron en este periodo y que comprendían las policromías aplicadas sobre todo tipo de soportes pictóricos: terracota, soportes murales, etc. A este respecto, son de destacar las aportaciones de Humphrey Davy, que analizó fragmentos de colores y morteros de Pompeya, de la pirámide de Cestius y de las Termas de Tito en Roma, así como de la célebre
} 
informaciones aportadas por la incipiente química del momento fueron decisivas para arrojar luz sobre los soportes, cargas y pigmentos involucrados en el policromado de los monumentos antiguos y sirvieron, además, como argumento definitivo para demostrar la relevancia y alcance de estos procedimientos, influyendo poderosamente en los debates sostenidos entre los defensores y los detractores de la policromía en piedra del pasado. El primer trabajo publicado en este sentido se refiere al artículo del químico y estadista francés Chaptal, de 1809, a propósito de los pigmentos hallados en las excavaciones de Pompeya. Nuevas aportaciones en este campo fueron los análisis llevados a cabo por los químicos Michael Faraday (Propileos y Teseion de la Acrópolis), W. Semper (hermano del arquitecto Gottfried Semper) y Landerer, sobre diversas muestras de policromía procedentes de Atenas, así como del francés Chevreul (Pompeya, templos de Júpiter y de la Concordia en Agrigento, templos de Selinunte y otros edificios de Sicilia). Ya en 1826, Geiger y Merimée indagan sobre los pigmentos empleados en el antiguo Egipto. Sin embargo, muy pocos de entre los nacientes museos, depositarios principales de las esculturas que procedentes de todo el mundo antiguo iban llegando a Europa, se hicieron eco de los resultados de estas experiencias científicas para incorporarlos a su discurso expositivo. Una excepción a esta regla fue la Glyptoteca de Munich: construida expresamente para exponer los frontones procedentes de Egina, restauró sus mármoles de acuerdo a las nuevas aportaciones de la ciencia, mostrándolos completamente policromados en fecha tan

pintura le Nozze Aldobrandine; Geiger, por su parte, estudió fragmentos de policromía provenientes de Pompeya y la Villa Adriana. Otros químicos involucrados en el estudio de obras de la antigüedad fueron los profesores J.F. John, R. Wiegmann, W. Abeken, etc., todos ellos activos a lo largo de la primera mitad del siglo XIX. temprana como 1816. Por su parte, el British Museum emprendería, entre los años 183637 , una serie de investigaciones para dilucidar la presencia o no del color sobre los mármoles procedentes del Partenón, así como en otras obras de la Antigüedad.

\section{LA POLICROMÍA SOBRE PIEDRA DE LOS ANTIGUOS Y SU IN- FLUENCIA EN EL ARTE DEL SI- GLO XIX.}

El descubrimiento de la policromía escultórica y arquitectónica de la Antigüedad tuvo también su reflejo en el arte del momento, siguiendo un camino casi paralelo a los hallazgos de la arqueología y la ciencia. De este modo, relevantes artistas y arquitectos activos a lo largo del siglo XIX tuvieron la inquietud de incorporar la estética recién descubierta a sus propios lenguajes. Si bien el desarrollo de este apartado merecería por sí mismo un monográfico, no queremos dejar de reseñar algunas de las personalidades que participaron de esta tendencia. En lo que concierne a la escultura, es notorio que John Gibson, el principal escultor inglés neoclásico, se dejara seducir por la policromía sobre mármol, como lo demuestra el retrato de la reina Victoria (1846) y sobre todo su Tinted Venus (h. 1854), cuyos cabellos, ojos, labios y pezones habían sido pintados de manera realista (Fig.7). Escultores de toda Europa, como Cailloué, Charles Cordier, Charles Simart, Carlo Marochetti, Ernest Barrias, Max Klinger, Jean-Léon Gèrôme (Fig. 8) y Fernand Khnoppf, entre otros, crearán obras policromas en los decenios siguientes, bien fuese aplicando pintura a la piedra, bien mediante la combinación policroma de diferentes materiales ${ }^{38} \mathrm{o}$ incluso sumando ambas posibilidades.

\footnotetext{
${ }^{38}$ Empleando la toréutica, la técnica acrolítica o el polilitismo.
} 
En la pintura destacan determinadas obras de Ingres que representan los interiores griegos vívidamente policromados $\mathrm{y}$, muy especialmente, del anglo-holandés Lawrence Alma-Tadema, que adoptaría plenamente los descubrimientos de la arqueología para sus recreaciones de episodios de la Antigüedad (Figs. 9 y 10). Otros pintores que realizaron obras en este sentido fueron Gustave Boulanger, o el mismo Gèrôme. La arquitectura, por último, no fue en absoluto ajena a la incorporación de un lenguaje policromo, ya que buena parte de los viajeros que dejaron constancia de la arquitectura policromada de los antiguos fueron arquitectos. A este respecto destacarán las obras de Leo von Klenze (Fig. 11), Friedrich von Gärtner (Fig. 12) y J.I. Hittorf, ${ }^{39}$ entre otros.

\section{CONCLUSIÓN.}

En el largo proceso que culminó con la afirmación de la importancia del color en la escultura y la arquitectura en piedra de la Antigüedad intervinieron una serie de factores, entre los que destacamos muy especialmente dos: por una parte, el descubrimiento y estudio de la estatuaria y arquitectura griegas policromadas, verificado desde fines del siglo XVIII; por otra parte, el desarrollo de la sensibilidad romántica, que en su pasión por lo exótico se dejó seducir por una estética sorprendente que estaba destinada a romper los estereotipos, firmemente establecidos, sobre el arte del mundo antiguo, acercándolo aún más a Oriente. Pero

\footnotetext{
${ }^{39}$ La desaparecida Maison Pompéienne, construida entre 1855 y 1860 para el Príncipe Napoleón en París y cuyo diseño fue encomendado en un primer momento a Hittorf constituyó una buena prueba de la presencia de policromías en la arquitectura y los interiores de inspiración grecorromana. También en París, y de la mano de J.I. Hittorf, se levantaría en 1852 el denominado Cirque d'Hiver, para cuyo exterior el francoalemán diseñó un friso con figuras destacadas sobre fondo rojo, claramente inspirado en los que tuvo ocasión de estudiar en los templos de Grecia.
}

además de los elementos citados, a la hora de superar los prejuicios existentes contra la policromía monumental coadyuvó de manera eficaz la incipiente química del momento, que se aplicó a la caracterización de las cargas y los pigmentos presentes en las capas pictóricas recién descubiertas.

La consecuencia natural de este cúmulo de elementos fue la aparición de publicaciones de diferente índole que dieron a conocer, tanto los hallazgos arqueológicos policromados que iban sucediéndose, como los estudios de todo tipo -artísticos, históricos, estético-filosóficos, científicos, etc.- a los que aquéllos dieron lugar. Esta misma literatura recogería, por otro lado, las disputas surgidas entre los defensores a ultranza de la pureza del mármol blanco para las creaciones artísticas y aquellos que se sintieron conmovidos ante la presencia del color sobre los monumentos del pasado y quisieron recuperarla para el presente.

En este sentido, la comunidad artística de comienzos del siglo XIX no fue en absoluto ajena a la nueva interpretación que ofrecía el arte de la Antigüedad. Tampoco lo fue su clientela, parte de la cual se dejó seducir por la policromía monumental. Este hecho favoreció no tanto la aparición de un arte nuevo como una serie de reinvenciones del clasicismo, donde los efectos de color, conseguidos pintando sobre la piedra o mediante la combinación de materiales, entraban a formar parte indisociable del conjunto de la composición. La serenidad del arte antiguo, noción en gran medida dependiente de la creencia neoclásica en la blancura de la escultura y la arquitectura en piedra del pasado, quedaba así definitivamente puesta en entredicho. 


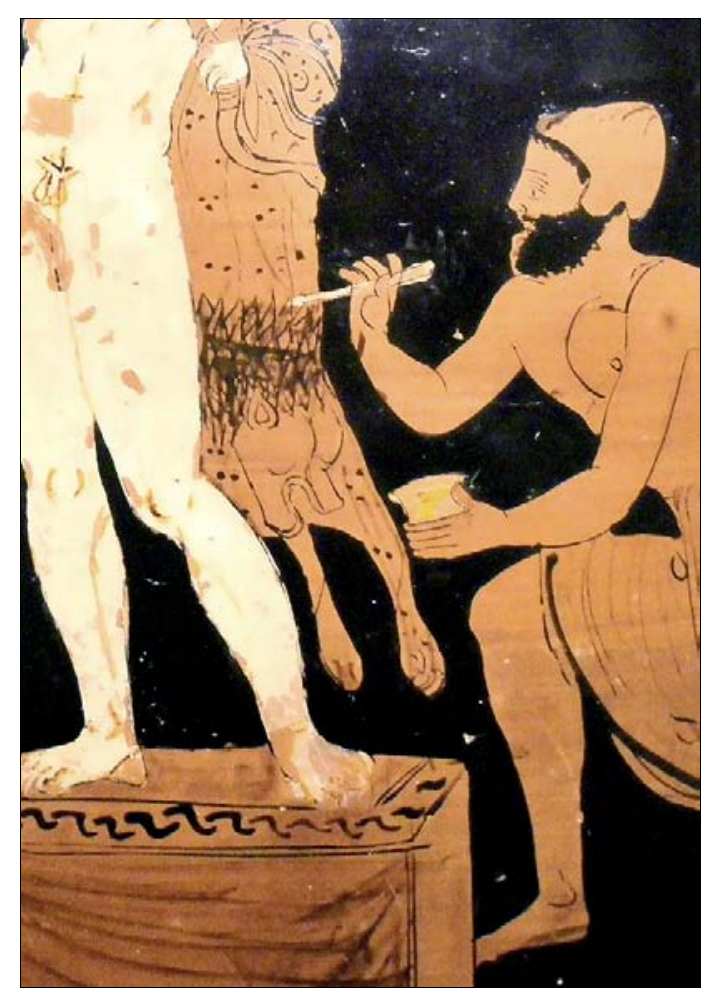

- Fig. 1. Pintor policromando una estatua de Heracles (detalle). Crátera griega (s. IV a.C.). Metropolitan Museum, Nueva York.

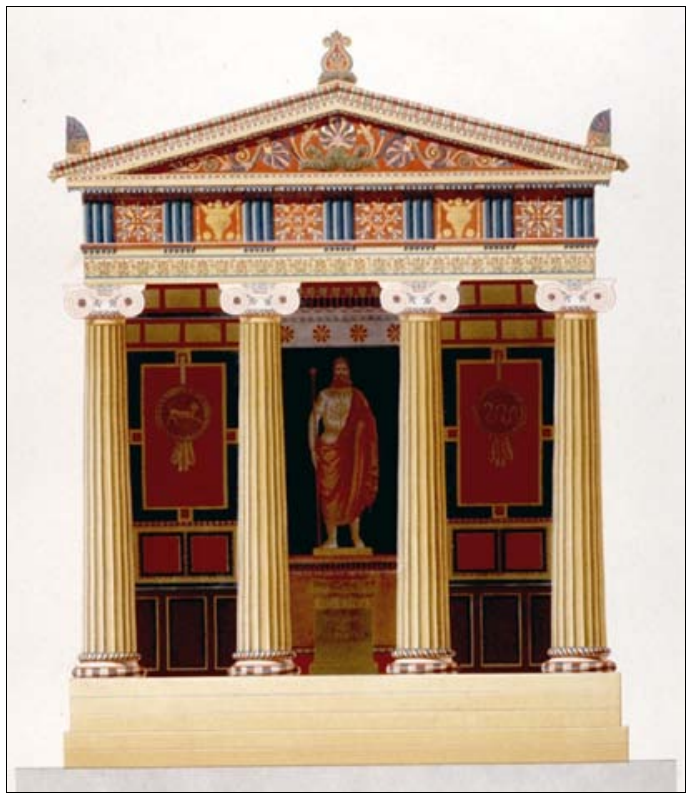

- Fig. 2. Jakob Ignaz Hittorf, Restitution $d u$ Temple d'Empédocle à Sélinonte ou l'Architecture polychrome chez les Grecs. París, 1851. Foto B.N.

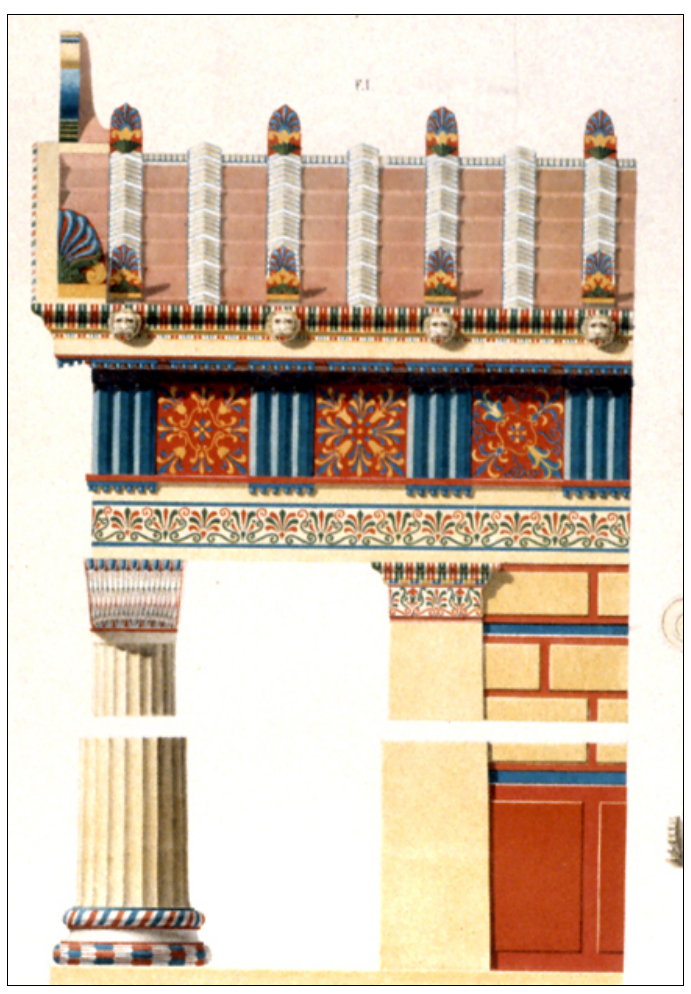

- Fig. 3. Jakob Ignaz Hittorf, Restitution $d u$ Temple d'Empédocle à Sélinonte ou l'Architecture polychrome chez les Grecs. París, 1851. Foto B.N.

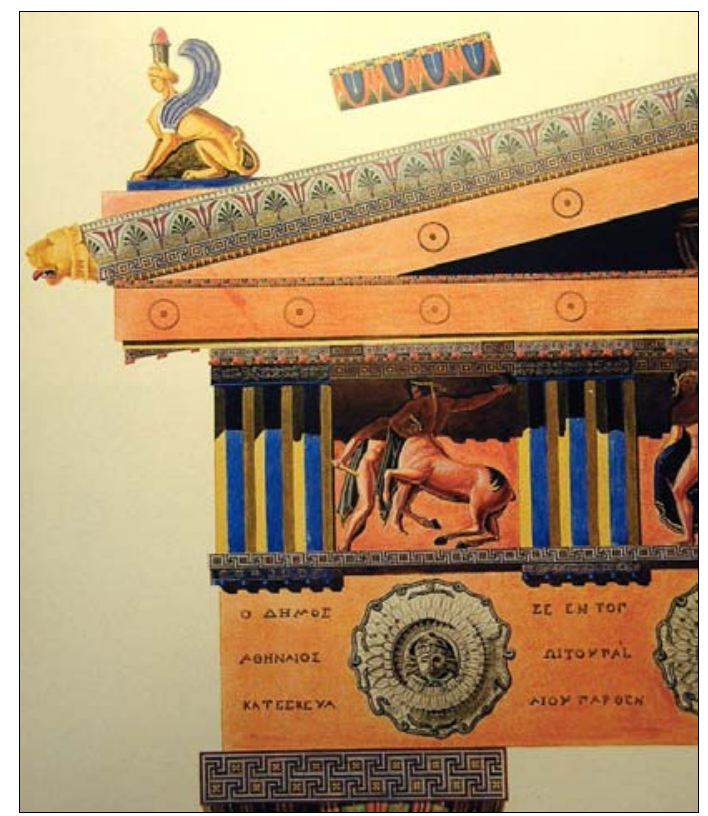

- Fig. 4. Semper: entablamento del Partenón, en Anwendung der Farben in der Architektur und Plastik (1836) 


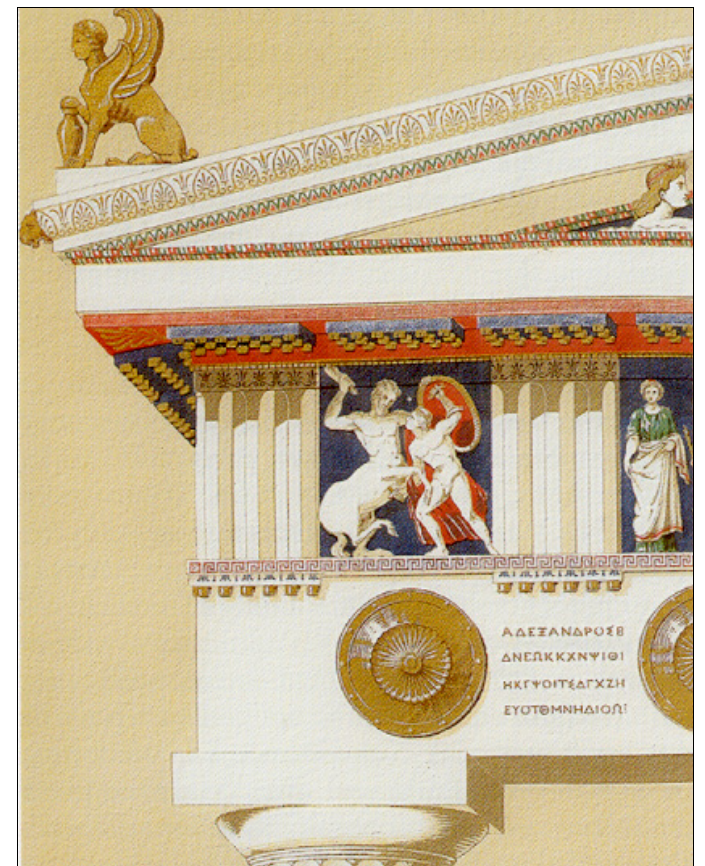

- Fig. 5. J. H. Strack: Frontón de la Acrópolis, en Franz Kugler, Über die Polychromie der griechischen Arkitektur und Skulptur und ihre Grenzen, Stuttgart 1835.

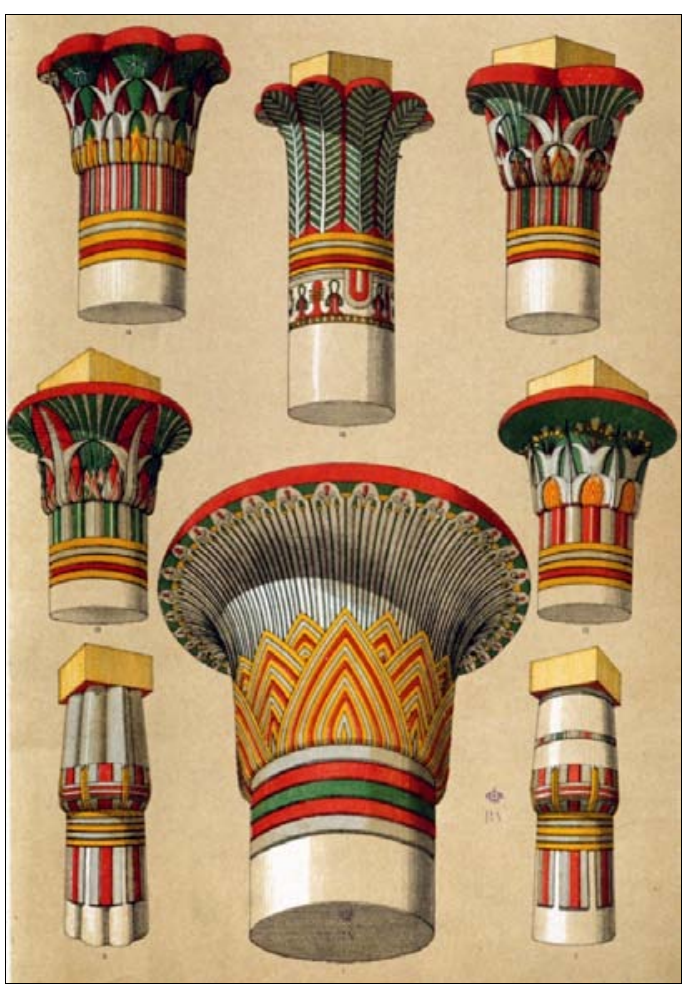

- Fig. 6. Capiteles y fustes de columnas egipcias. Owen Jones, The Grammar of Ornament. Londres, 1856. Foto B.N.

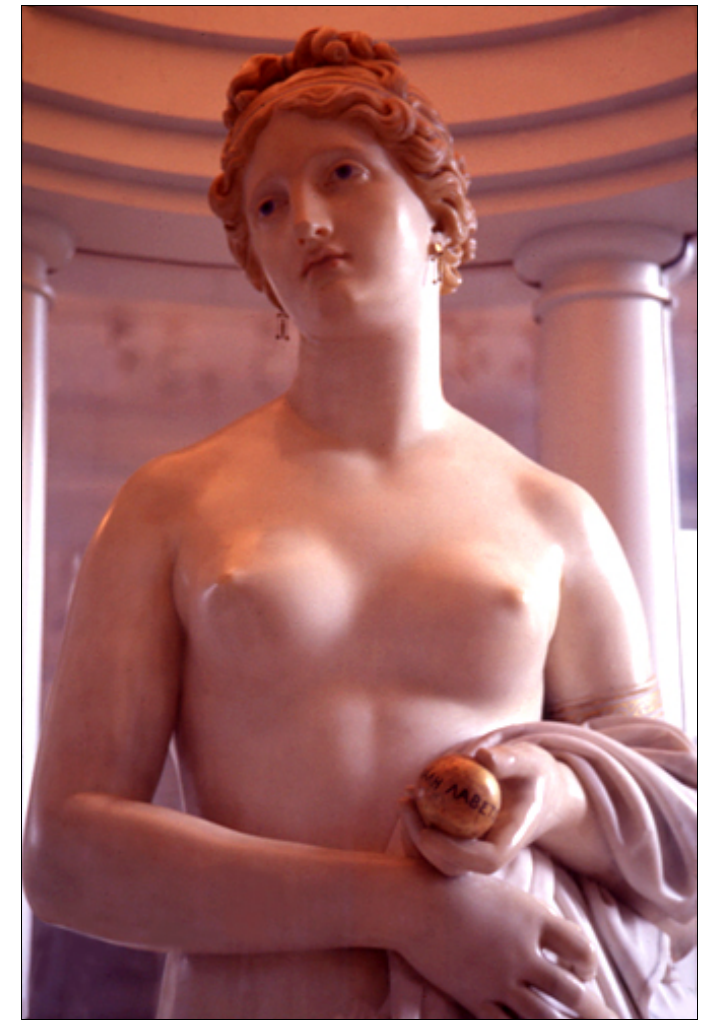

- Fig. 7. John Gibson, The Tinted Venus (h. 1854). Mármol policromado, $175 \mathrm{~cm}$. Walker Art Gallery, Liverpool.

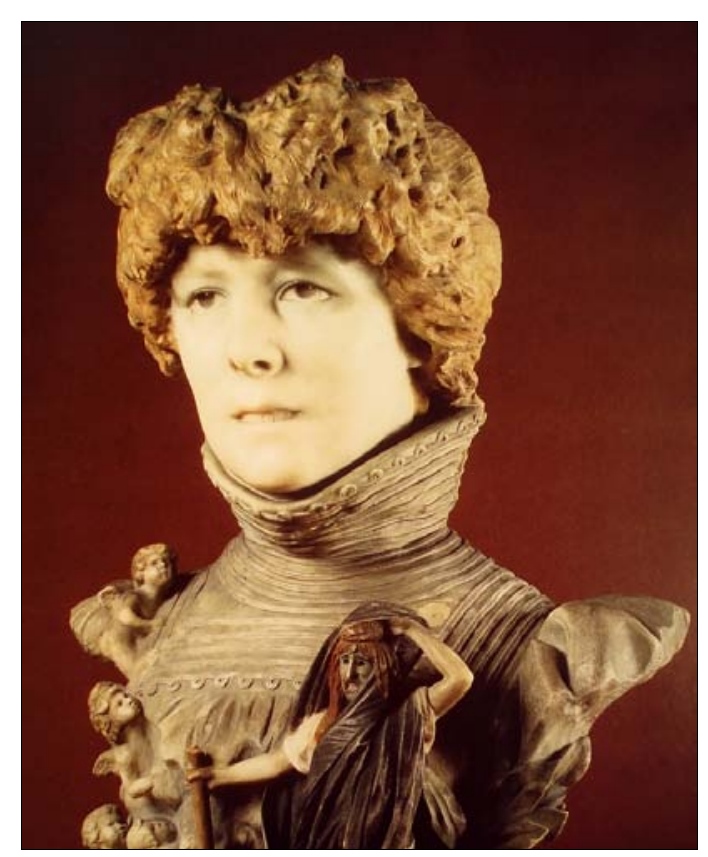

- Fig. 8. Jean-Léon Gérôme, Sarah Bernhardt (1895-97). Mármol policromado, 67,7 x 41 x $29 \mathrm{~cm}$. Foto Musée d'Orsay. 


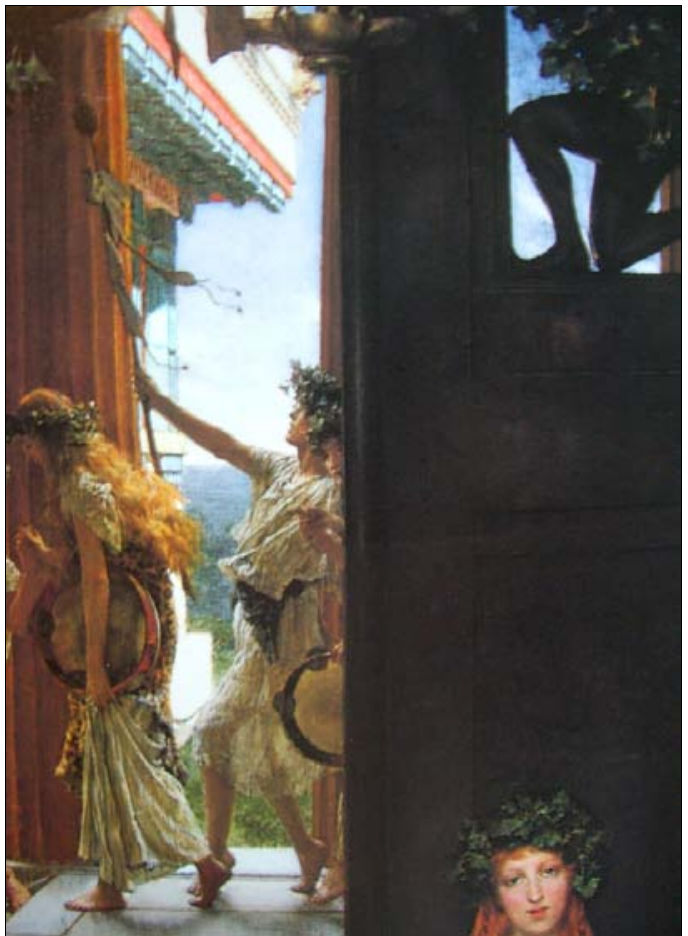

- Fig. 9. Lawrence Alma-Tadema, The Way to the Temple (detalle). 1882. Óleo sobre lienzo. $101,5 \times 53,5 \mathrm{~cm}$. Royal Academy of Arts, Londres.

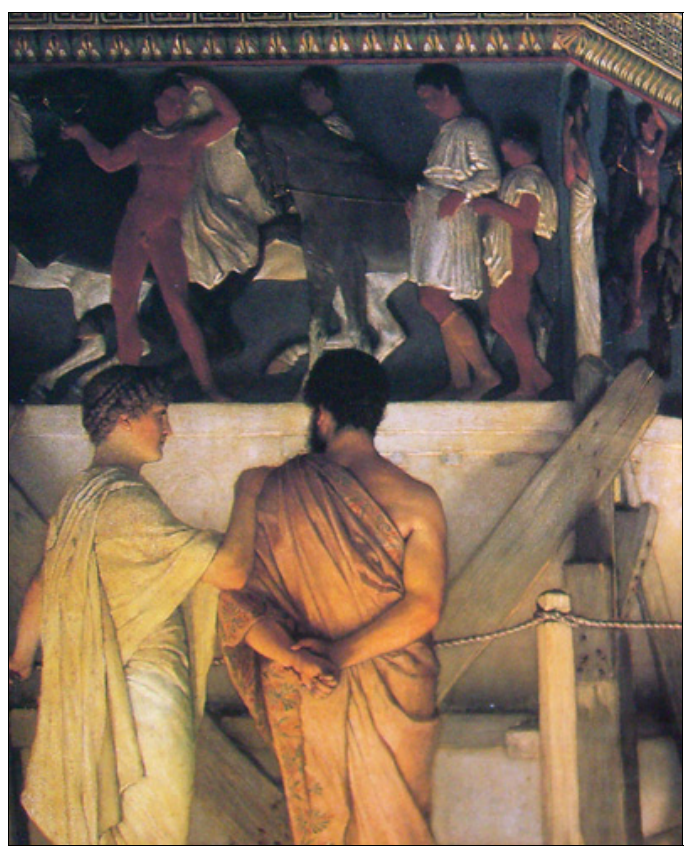

- Fig. 10. Lawrence Alma-Tadema, Phidias showing the Frieze of the Partenon to his Friends (detalle). 1868-69. Óleo sobre tabla. 72 x 110,5 $\mathrm{cm}$. Birmingham Museums and Art Gallery.

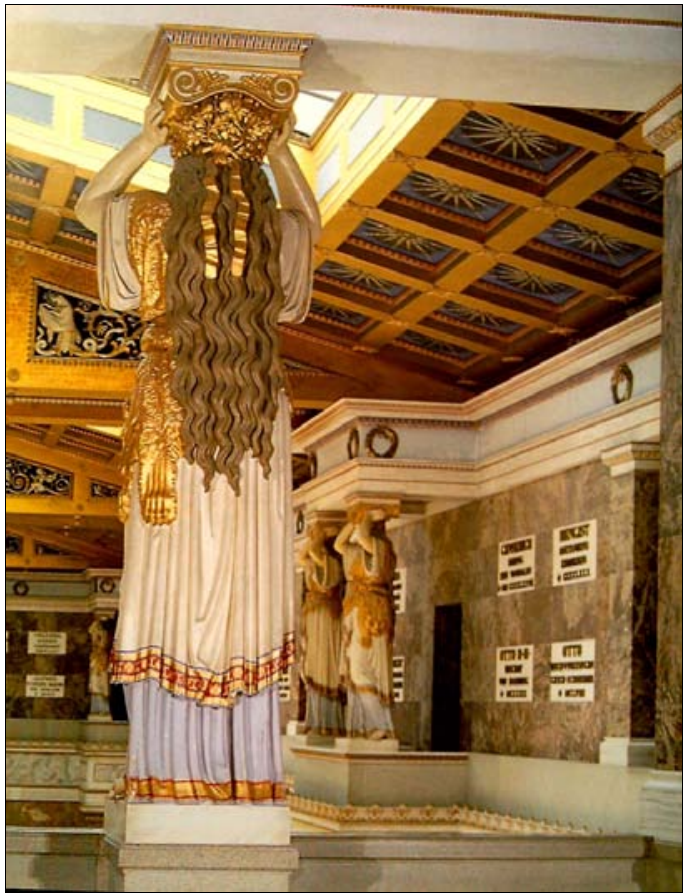

- Fig. 11. Leo von Klenze (arquitecto) y Ludwig von Schwanthaler (escultor), Walhalla, 1830-1842. Regensgburg (Alemania).

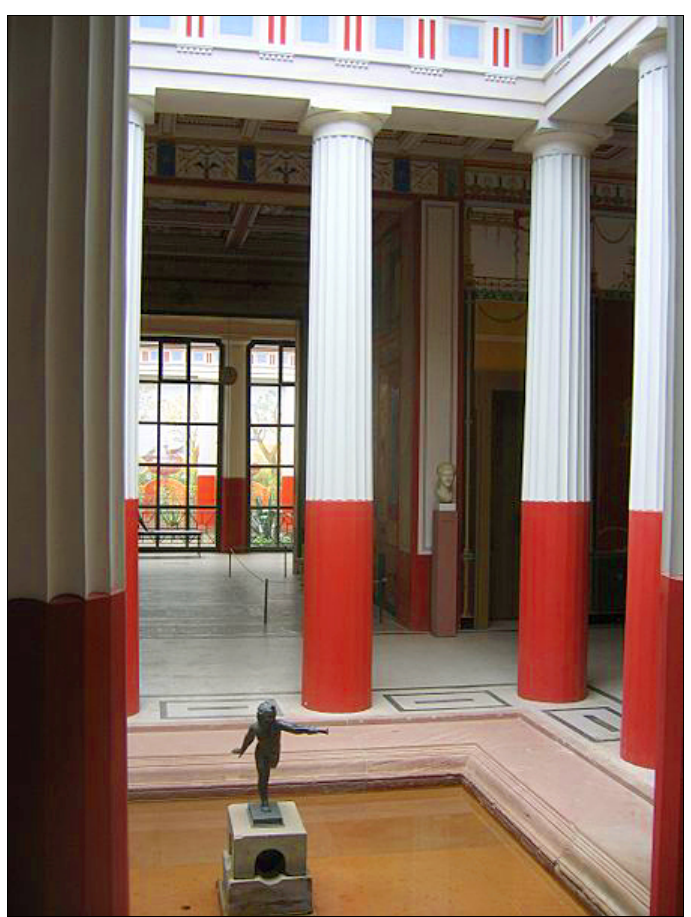

- Fig. 12. Friedrich von Gärtner, Pompejanum, 1840-48. Residencia en Aschaffenburg (Alemania), que recreaba una villa de Pompeya o Herculano. 